health and strength that, in the long run, follows insufficient sleep. In spite of the prolonged inquiry, the Committee's proposal, although it is ostensibly an appreciation of daylight, appears to many persons, and those not all indolent or conservative, to be nothing more or less than a proposal for a leap in the dark.

\section{WOMEN AND THE FELLOWSHIP OF THE CHEMICAL SOCIETY.}

THE women, like the Peris at Heaven's Gate, have knocked at the door of the Chemical Society and have asked to be let in. Their request, as will be seen from the correspondence which we print below, has been referred to the whole body of the fellows, and there are those among them who are much perturbed in consequence. The more excited ones, we understand, are all for banging, barring and bolting, unmindful of the portents that a banging, barring and bolting policy is nowadays a bit discredited. Others, and we trust, for the fair fame and credit of the society as a scientific organisation, that they are the majority, are of opinion that the time has come when its fellowship should be rendered accessible to women. At least, so say the 312 fellows (including Io past presidents, I2 vice-presidents, and 29 members of council, past and present), among whom are 33 Fellows of the Royal Society, and the heads of the chemical departments of nearly all the most important universities and colleges in the kingdom, who have now moved the council, by the most influentially signed memorial that body has ever received, to consent to the referendum.

It is difficult to know on what grounds the admission of duly qualified women to the society should be refused. Those who desire admission have been adequately trained in science, and most of them are graduates. They are, as pointed out by Sir Henry Roscoe in a letter to the Times of July 3 , de facto chemists, engaged either as lecturers or demonstrators of chemistry in various schools or colleges throughout the country; some of them act as research assistants to professors of chemistry, or cooperate with them in the work of original inquiry; one or two are employed as works-chemists. The objects of the Chemical Society are defined to be the promotion of chemistry, and of those branches of science immediately connected with it, by the reading, discussion, and subsequent publication of original communications. It cannot be denied that women have contributed their fair share of original communications. Indeed, in proportion to their numbers they have shown themselves to be among the most active and successful of investigators. The society consents to publish their work, which redounds to its credit. Why, then, should the drones who never have done, and never will do, a stroke of original work in their lives be preferred to them simply because they wear a distinctive dress and are privileged to grow a moustache?

The women-chemists will doubtless smile at the futility of the adverse arguments which appear above the names of the two honorary secretaries of the society. They will have their own opinion concerning the arduous nature of chemical work, about which they know quite as much as those who profess so tender a solicitude for them. As to their chances of success in life, they have shown that they are quite able to hold their own, in spite of the alleged " overcrowded state of the profession." Overcrowded state of the profession, forsooth! With a delicious but wholly unconscious naiveté, the banging, barring and bolting people have herein revealed the true inwardness of their opposition. It is the argument of the weak-kneed-of persons whose Zunftgeist has warped their judgment and disturbed their mental balance. We trust the main body of the society will treat the argument with the contempt it merits. It is astonishing how unscientific some so-called scientific persons can be. Apparently they fail to perceive that this request on the part of qualified women to be permitted to share the benefits and material advantages which arise from the cooperation of scientific workers in a common calling is the natural and logical result of affording women facilities for the cultivation of science in practically every university in the country. The study of science, even professionally, is no longer the exclusive prerogative of men. It was inevitable that among the many hundreds of women who are now passing through these universities, or through colleges in close association with them, there should be some who are attracted to science as a calling, or who should find in its pursuit a congenial occupation. They are surely entitled to make their own choice of their life's work. Why, then, should obstacles be thrown in their way? They ask for no favour-only for fair play and fair treatment, and it is the banging, barring and bolting people who, from unworthy motives, would deny them both.

A perusal of the correspondence which we publish below, and especially of the significant letter of the past presidents of the society accompanying the memorial addressed to the council which they have caused to be distributed to the fellows of the society, indicates pretty clearly to what lengths certain individuals are prepared to go in resisting the claims of the women. The memorial, it will be seen, expressed the personal opinion of the 312 signatories that the time had come when the fellowship should be rendered accessible to women, but that weighty fact is not mentioned in the letter which appears above the names of the secretaries. This was neither fair to those who signed the memorial nor to the women whose cause they had taken up. It is possible that this suppressio veri was unintentional, nor is it likely, we imagine, that there is any arrière pensée in the redundant words to which the past presidents direct attention and which serve only to confuse the issue. But those who drafted the letter and the accompanying ballot-paper must at least be held responsible for the bungling, maladroit manner in which the matter was presented to the fellows. It is a question for the society whether its true interests would not be better served by the transference of its secretarial business to more competent and more judicious hands.

\section{Letter from the Secretaries of the Chemical Society to} the Fellows.

\section{Burlington House,} Piccadilly, W. June, 1908

DEAR SIR,

The Council of the Chemical Society have received a petition praying for an inquiry as to the views of the Society as a whole on the question of admitting women to the Fellowship.

Accordingly, the Council invite very careful consideration of the following brief statement of the chief arguments which have been used both for and against the admission of women.

It is proper to point out that the Council were advised on a former occasion by Counsel that there is some doubt whether, under the existing Charter, women are admissible as Fellows; it is also well to remember that if admitted to this status, women would be eligible, like other Fellows, for a seat on the Council and to hold office.

Those who support the view that steps ought to be taken in order to provide for the admission of women to the Fellowship point out-

(I) That the petition has been signed by 312 Fellows (including to Past Presidents, 12 Vice-Presidents, and 29 
Members of Council, past and present), among whom are 33 Fellows of the Royal Society and the Professors of Chemistry or Heads of Chemical Departments of nearly all the most important Universities and Colleges in the country.

(2) That a number of women are now devoting themselves to the science of Chemistry, the study of which it is the chief object of the Chemical Society to promote. It is shown that they are capable of independent work by the facts stated in the petition; moreover, in the Transactions from January to May this year there are four papers by women authors independently of others in which they appear as joint authors.

(3) The Chemical Societies of Berlin and America and the Institute of Chemistry admit women to full privileges of membership. The Chemical Society itself has placed the name of Madame Curie among those of its Honorary Members.

(4) A small number of women chemists attend the meetings of the Society regularly as visitors, and no inconvenience has arisen from their presence. They ask that they should be admitted in order that, in addition to exercising the voting powers, they may use the Library and receive the publications of the Society on the same terms as Fellows; at present they have to pay the higher price of publication charged to the general public.

(5) The Society numbers more than 2800 Fellows, while the number of women desiring admission at the present time is about 2o; this number will probably increase as time goes on, but judging by the experience of other Societies, it is not likely greatly to exceed that number in the present generation. Should the number rise to as many as 50 , their numerical strength would remain wholly insignificant in regard to the conduct of the Society's affairs; consequently, any fear that female influence might hereafter dominate the Council, or even that one woman might be elected to the Council except only in recognition of her scientific ability, is not worth consideration. As to the undesirability of substituting one sex for another in offices of employment, little argument can be based on such a consideration so long as men continue to hold many of the teaching posts in women's colleges.

(6) There is reason to believe that in the event of a decision in favour of applying for a supplemental Charter, the cost, or a large part of it, would be borne by the women chemists and their friends.

On the other hand, those who are unwilling to admit women to the Fellowship of the Chemical Society urge that-

(I) The expense, probably amounting to several hundred pounds, which would be incurred by the Society if a supplemental Charter is necessary, is not justified by the small number of new Fellows likely to seek admission.

(2) It may be gravely doubted whether the deliberate encouragement of women to enter the chemical profession would not operate unfavourably on women themselves in view of the arduous nature of chemical work.

(3) Although it is true, as urged by supporters of the petition, that the number of women seeking admission is small, it is also claimed as a reason for admission that the volume of chemical work contributed by women is increasing rapidly. So long as the women who desire admission remain in such disproportionate minority, there will be an inevitable-although, of course, involuntarytendency to overestimate their contribution to chemical knowledge and practice. An illustration of this principle may fairly be drawn from the petition itself, where figures are adduced to show that during the past thirty-five years women have been associated with 103 Papers contributed to the Transactions of the Society, but it is not stated, though equally true, that while the total number of Papers printed during that period exceeds 3400 , only twenty-three are in the names of women alone.

(4) Even assuming that these 23 contributions were independent of masculine inspiration, it may be questioned whether women have, as a group, shown marked. aptitude for chemical pursuits, particularly when it is recalled that the authors in question have worked almost exclusively in collegiate institutions.

(5) Moreover, by being welcomed as guests to the Society, women have been able to enioy that chemical No. 20I9, VOL. 78] atmosphere and intercourse which Fellowship of the Society involves.

(6) As regards the admission of Madame Curie to Honorary Membership, it must be borne in mind that Honorary and Foreign Members have no voting powers, and are not eligible for office.

(7) Briefly stated, the position of those unfavourable to the admission of women is that, whilst gladly offering to those women who already have become chemists measures which would give them the benefits derived from attendance at the meetings, they deem it inexpedient publicly to encourage women to adopt chemistry as a professional pursuit, since such a course would tempt them into a career in which they may ultimately not find employment in view of the already over-crowded state of the profession.

Other minor considerations might be mentioned on both sides, and rejoinders to all the above statements are generally obvious. The Council therefore hope that every Fellow will carefully consider the arguments on both sides, and give them the weight which each, respectively, appears in his judgment to deserve.

You are requested, after making the necessary deletion, to return the enclosed ballot paper to the Secretaries in the accompanying envelope, which envelope must be endorsed with your signature. Unsigned envelopes and signed ballot papers will be invalid.

The ballot will close on the first day of October next.

$$
\text { We are, Sir, }
$$$$
\text { Yours faithfully, }
$$

Arthur W. Crossley.

(Hon. Secretaries.)

Letter from Past Presidents communicating the Memorial to the Fellows.

$$
\begin{aligned}
& \text { OXFORD, } \\
& \text { Ist July, } 1908 .
\end{aligned}
$$

DEAR Sir,

In the letter, which has been sent by the Secretaries of the Chemical Society to every Fellow, on the question of admitting Women to the Fellowship, reference is made to a petition received by the Council. We think it desirable that the petition itself, which is not only a petition but a declaration of opinion on the part of a large body of the Fellows of the Society, should be made known generally, together with the names of those by whom it was signed. Accordingly we enclose herewith a copy of the petition as presented to Members of the Council.

Before the issue of the voting papers the attention of the Secretaries was called to an ambiguity which is due to the introduction of the words "the full rights and privileges of." We suggest that those Fellows who are in favour of the admittance of women to the Fellowship, and not only to "the full rights and privileges of the Fellowship," should strike out these words. It would clearly be possible, however unreasonable, to create a class who, though not actually Fellows, were admitted to all the rights and privileges of the Fellowship. That such a class should be created is not the question which the Council were asked and consented to put.

$$
\begin{aligned}
& \text { We are, Sir, } \\
& \text { Yours faithfully, }
\end{aligned}
$$

(Signed)

\section{William Odling.}

William Crookes.

A. VERNON Harcourt.

HenRy E. ROSCOE.

Hugo MÜller.

W. J. RusséL.

T. E. THORPE.

J. EMERSON Reynolds.

William A. Tilden.

R. Meldola.

Alex. Crum Brown.

Memorial addressed to the President and Council of the Gentlemen, Chemical Society.

We, the undersigned Fellows of the Chemical Society, being of opinion that the time has come when the Fellowship of the Society should be rendered accessible to women, 
request the Council to take such steps as may appear desirable to ascertain the wishes of the Society as a whole in regard to this question.

We understand that there is now an appreciable and increasing number of women of University training engaged in advanced teaching, and in original investigation in chemistry, who desire admission to the privileges of the Fellowship, and as the Chemical Society was founded for the advancement of Science, it seems to us neither just nor expedient that a body of highly qualified workers should be excluded solely by reason of sex.

From the following table, compiled from the Society's journal of the past 35 years, it will be seen that the number of Papers contributed either alone, or jointly, by women is increasing rapidly :-

\begin{tabular}{|c|c|c|c|c|c|c|}
\hline \multirow{3}{*}{ I $873-82$} & \multirow[b]{3}{*}{$\ldots$} & \multicolumn{5}{|c|}{ No. of papers published in } \\
\hline & & & Seedi & & & hactions \\
\hline & & $\cdots$ & 2 & $\ldots$ & $\cdots$ & 2 \\
\hline & $\cdots$ & $\cdots$ & 7 & $\cdots$ & $\ldots$ & 7 \\
\hline & $\cdots$ & ... & 45 & $\ldots$ & $\ldots$ & 33 \\
\hline 07 & $\ldots$ & $\ldots$ & 66 & $\ldots$ & $\ldots$ & 61 \\
\hline
\end{tabular}

We may further point out that not only have women contributed original memoirs to these publications, but they have rendered valuable service to the Society as abstractors and in the compilation of the Indexes.

As is well known, the Chemical Societies of Berlin and America, the Society of Chemical Industry and the Faraday Society, admit women on the same terms as men, and our Society has found a place for Madame Curie among the Honorary and Foreign Members: we consider, therefore, that the restriction should be removed under which the Chemical Society denies to women chemists the advantages extended to them by the sister Societies at home and abroad.

\section{We are, Gentlemen,}

Your obedient Servants.

Here follow the names of the 312 Fellows (including Io Past Presidents, I2 Vice-Presidents and 29 Members of Council, past and present), among whom are 33 Fellows of the Royal Society and the Professors of Chemistry or Heads of Chemical Departments of nearly all the most important Universities and Colleges in the country.

\section{NOTES.}

IN connection with the celebration of the tercentenary of the birth of Evangelista Torricelli, an exhibition will be held at Faenza from August 15 to October 15. Included in the programme, and associated with an international section for physical apparatus, in celebration of Torricelli, a prize of 2000 lire is offered for an instrument in connection with meteorology or physics of the earth. The instrument must be exhibited, and show real novelty, either in its principle or in its application of a principle already known. For further particulars application should be made to Dr. W. N. Shaw, F.R.S., Meteorological Office, 63 Victoria Street, London, S.W.

From July $I$ the morning hour of observation in the British Isles for the Daily Weather Report of the Meteorological Office has been changed from 8 a.m. to 7 a.m., and that of the midday observation from $2 \mathrm{p} . \mathrm{m}$. to I p.m. At only two of the twenty-nine stations have the earlier observations been found impracticable. Simultaneously, arrangements have been made for the transmission of the telegraphic reports from all the stations, except one, at which the early observations are made, and for attendance at the office in Victoria Street at the same hour to receive the messages. It is anticipated that the revised arrangements, by which the observations in this country become synchronous with those of France, Belgium, Holland, Germany, Denmark, Iceland, Norway, and Sweden will lead, when fairly established, to a considerable accelcration of the morning reports.

NO. 20I9, VOL. 78$]$
BRILLIANT sky-glows were observed in many different parts of the United Kingdom on the night of June 30 and on several succeeding nights, the phenomenon being apparently at its maximum intensity on the night of July $x$. The whole of the northern part of the sky, from the horizon to an altitude of about $45^{\circ}$, and extending to the west, was suffused with a reddish hue, the colour varying from a pink to an Indian red, whilst to the eastward of north the colouring was distinctly a pale green. No flickering or scintillation was observed on the reddened sky, nor was there any tendency to the formation of the streamers or luminous arch characteristic of auroræ. Cirro-stratus clouds near the horizon were tinged with the same colour as the surrounding sky. A special feature in connection with the phenomenon was the prolongation of twilight, extending almost to the following daybreak, and from the experience cited by many observers in various parts of Great Britain the light at midnight was sufficient to allow of fairly small print being read without any aid from artificial light. These nocturnal glows were preceded by a drought extending in London, as well as in several other parts of England, to about sixteen days, and it was followed by severe thunderstorms on the night of July 3 and on the succeeding day. The fine weather in many parts of the country has, however, remained unbroken, so that no relation between the display and disturbed weather can be claimed. Miss C. O. Stevens, who describes a long-sustained solar halo in our correspondence columns, made observations of the coloured skies on the nights of June 30 , and July I and 2, until daybreak obliterated them. She says :- "The naked-eye evidence favours the view that the phenomenon was due, in part at least, to auroral display, both in the brilliant white and delicate green patches of light that were of rather inconstant brilliance, and in the spreading of the rosy light into the far south and southwest at 1.45 a.m. on July I." We are informed, however, that spectroscopic observations failed to give any evidence that the phenomenon was auroral in character.

THE death is announced, at the age of eighty-four, of Prof. J. V. Barbosa du Bocage, director of the Zoological Institute at Lisbon.

THE death is announced, in his seventy-third year, of Prof. C. Schrader, the leading authority in Germany on the Assyrian language and Assyrian civilisation.

The prize of 10,000 francs (40ol.) offered by M. Armengaud to the first aëroplane to remain in the air for a quarter of an hour was won by Mr. Farman on Monday, at a competition held at Issy-les-Moulineaux, under the auspices of the Aéro Club. Mr. Farman made a flight with his apparatus which lasted 20m. 20s. according to the official timing. He covered a distance of about eleven miles.

Count ZePpelin last week made a remarkably successful flight in his new airship. The airship started on its voyage from Friedrichshafen at $8.30 \mathrm{a} . \mathrm{m}$. on July I, and headed for Switzerland. After executing evolutions over Lake Constance, the airship proceeded in the direction of Lucerne, where it was seen at 12.30 p.m. The return northwards was over lakes Zug and Zürich, and the airship was observed over the town of Zürich at 2.20 p.m. The airship's floating shed on Lake Constance was reached at $8.30 \mathrm{p} . \mathrm{m}$. The distance covered is estimated at 250 miles, and the journey lasted twelve hours. The greatest height reached by the airship's own engine-power is stated to be some $75^{\circ}$ metres, and the highest speed ${ }_{15} .3$ metres per second. It will be remembered that the previous record 